\title{
Study of ambulatory care supervision mechanisms in health systems: A comparative study
}

\author{
Maryam Seyedjavadi ${ }^{1}$, Mehdi Jafari ${ }^{1,2}\left(\mathbb{D}\right.$, Hamid Ravaghi $^{1}$, Aidin Aryankhesal ${ }^{1}$
}

Received: 21 Jul 2020

Published: 3 Nov 2020

\section{Abstract}

Background: Supervision in health sector means a system, process, or mechanism by which some aspects or characteristics of a health care organization is evaluated and analyzed by an external body. This study compared the mechanisms of supervision in ambulatory care in selected countries to provide lessons learnt from global experiences.

Methods: In this comparative study USA, UK, Germany, Canada, Turkey, and Iran were selected based on inclusion criteria, including development level and type of the health system. Required data were gathered by searching the internet, browsing the websites of related organizations, and searching research databases. Then, the results were summarized and reported using comparative tables.

Results: Some regulations and frameworks exist for assuring and improving the quality and safety of the services in all health systems. The supervising bodies of this subject include central and local governments along with nongovernmental organizations. The supervision in studied countries is mostly compulsory and unannounced. Moreover, accreditation of ambulatory care exists voluntarily and compulsorily. Results of the supervision include temporary or permanent suspension of license for care provision, impact on payment to the providers, and change in popularity of the provider by public communication of the result.

Conclusion: Improving the supervision on ambulatory care requires an effective structure for separation of provider and supervisor and the involvement of the professional associations. It is suggested to elevate the ambulatory care supervision through better resource allocation, follow up of the supervision results, enforcement of regulations, and application of novel approaches.

Keywords: Supervision, Ambulatory care, Quality, Safety, Comparative study

Conflicts of Interest: None declared

Funding: Iran University of Medical Sciences (IUMS), Grant number: IUMS/SHMIS_1396.9321532001.

*This work has been published under CC BY-NC-SA 1.0 license.

Copyright $₫$ Iran University of Medical Sciences

Cite this article as: Seyedjavadi M, Jafari M, Ravaghi H, Aryankhesal A. Study of ambulatory care supervision mechanisms in health systems: A comparative study. Med J Islam Repub Iran. 2020 (3 Nov);34:148. https://doi.org/10.47176/mjiri.34.148

\section{Introduction}

In the health sector supervision is defined as a system, process, or mechanism by which some aspects and activities of a health care provider organization are evaluated and analyzed by an external body based on a framework

Corresponding author: Dr Mehdi Jafari, mjafari@iums.ac.ir

1. Department of Health Services Management, School of Health Management \& Information Sciences, Iran University of Medical Sciences, Tehran, Iran

2. Health Managers Development Institute, Ministry of Health and Medical Education, Tehran, Iran of ideas, knowledge, and criteria. Thus, supervision systems are important in health care for their impact on patient outcomes and cost reduction, achieving patientoriented care, as well as promotion of improvements in

$\uparrow$ What is "already known” in this topic:

Tendency to the ambulatory care is growing due to increased life expectancy, advances in diagnostic and therapeutic methods towards less-invasive ones, and cost reduction efforts. This highlights the importance of supervision for safety of these services. Yet, few studies had examined the supervision of ambulatory care.

$\rightarrow$ What this article adds:

This study compared the supervision mechanisms of ambulatory care in 5 countries with various health systems. It identified the responsible bodies for this supervision, types of supervision, and consequences of supervision. Then, discussed the lessons learnt from global experiences. 
quality, changes in structures and processes, and changes in provider behaviors (1-3).

Ambulatory care centers are those health care organizations in which the health care is provided to the patients while they are not hospitalized. These cares include a wide variety of services from doctors' offices to clinics and the ambulatory surgery centers (4). It seems the ambulatory parts of the health care are ignored in efforts to regulate, improve the quality and safety, and reduce the medical errors. This is while the ambulatory care is extending in terms of methods and numbers. New techniques and medicines have made more ambulatory surgeries possible so that $65 \%$ of all surgeries do not require hospital stay. It is also estimated that $10 \%$ to $20 \%$ of all elective surgeries are performed in ambulatory surgery centers because of the $60 \%-75 \%$ lower costs than the hospitals (5).

On the other hand, as technology progresses, the ambulatory methods and the mortality and morbidity due to these methods may increase (6). Poor supervision on the regulations and guidelines of the Ministry of Health results in medical errors and in turn leads to conviction in lawsuits and compensation. Medical errors are also responsible for inappropriate quality of care, patient dissatisfaction and complaints. International evidence shows that despite the scientific and technology advances in medical sciences, patient complaints have been growing in recent years $(7,8)$.

In most countries national and social entities, on behalf of the general public, supervise the quality and effectiveness of the health care. This function seems inevitable when considering the increased demand and costs of the health care services. Comprehensible and applicable feedback of the results of this supervision to the policymakers, health care managers, and the public are seen in national and local policies in these countries (9-14).

Similarly, the increased demand due to increased life expectancy, along with the advances of diagnostic and therapeutic technologies, has resulted in a movement towards ambulatory and less invasive methods (15). Thus, supervision methods in the ambulatory services should employ new effective mechanisms to assure the quality and safety of the services and to meet the legal considerations and protection of the patients. This study compared the supervision mechanisms for ambulatory care of the selected countries to provide the lessons learnt from global experiences.

\section{Methods}

This comparative study was conducted in 2020 to compare the supervision mechanisms of the ambulatory care in the selected countries. Criteria for selecting countries were development level according to the United Nations classification (16) to include both developed and developing countries; type of the health system of the country (17, 18 ) to include countries with all 3 types of health systems (public insurance, social insurance, and private insurance); and availability of evidence in English language.

USA, UK, Germany, Canada, Turkey, and Iran were selected based on the inclusion criteria. The required data were gathered from published materials by searching the internet, browsing the website of the related organizations such as World Health Organization (WHO) and searching the research databases. A researcher-developed form was used for data extraction. The form was developed based on literature review, research question, and the opinions of the research team. Items considered for data collection include general information about health systems and their ambulatory care provision, responsibility for supervision, supervision mechanisms (complaint- based or routine supervision or accreditation) and consequence of supervision. As this was a descriptive-comparative study, the data were analyzed using comparative tables.

\section{Results}

\section{Health system and the ambulatory care provision}

Based on health system types and financing, various mechanisms are observed for providing ambulatory care globally, which range from public provision to publicprivate partnership (PPP). Ambulatory care mostly con-

Table 1. Health system and ambulatory services in selected countries

\begin{tabular}{|c|c|c|c|c|c|c|c|c|c|c|}
\hline \multirow[b]{2}{*}{ Country } & \multirow[b]{2}{*}{ Government/ Political structure } & \multirow[b]{2}{*}{ Population $^{l}$} & \multicolumn{2}{|c|}{$\begin{array}{c}\text { Current health } \\
\text { expenditure }\end{array}$} & \multicolumn{2}{|c|}{$\begin{array}{c}\text { Ambulatory } \\
\text { care provision }\end{array}$} & \multicolumn{4}{|c|}{$\begin{array}{l}\text { Ambulatory care } \\
\text { providers }\end{array}$} \\
\hline & & & $\begin{array}{l}\frac{\partial}{0} \\
\frac{0}{0} \\
\frac{1}{2}\end{array}$ & $\frac{\overbrace{0}^{\circ}}{\overbrace{0}^{0}}$ & $\stackrel{0}{\frac{10}{3}}$ & 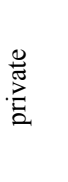 & 胥 & 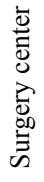 & $\stackrel{\mathscr{Z}}{\rightrightarrows}$ & 胥 \\
\hline Canada & $\begin{array}{l}\text { constitutional monarchy/ the federal government } \\
\text { and } 10 \text { provinces }\end{array}$ & 37058000 & 70 & 30 & $\sqrt{ }$ & $\sqrt{ }$ & $\sqrt{ }$ & & $\sqrt{ }$ & \\
\hline Germany & $\begin{array}{l}\text { Federal Republic/ federal parliamentary republic } \\
\text { and } 16 \text { Länder }\end{array}$ & 82927000 & 77 & 23 & $\sqrt{ }$ & $\sqrt{ }$ & $\sqrt{ }$ & & $\sqrt{ }$ & \\
\hline Turkey & Republic of Turkey/ parliamentary democracy & 82319000 & 73 & 27 & $\sqrt{ }$ & $\sqrt{ }$ & $\sqrt{ }$ & & $\sqrt{ }$ & \\
\hline UK & constitutional monarchy/ parliamentary system & 66488000 & 83 & 17 & $\sqrt{ }$ & $\sqrt{ }$ & & & $\sqrt{ }$ & $\sqrt{ }$ \\
\hline USA & $\begin{array}{l}\text { federal constitutional democracy/ federal system } \\
\text { and } 50 \text { states }\end{array}$ & 327167000 & 48 & 52 & $\sqrt{ }$ & $\sqrt{ }$ & $\sqrt{ }$ & $\sqrt{ }$ & $\sqrt{ }$ & $\sqrt{ }$ \\
\hline Iran & $\begin{array}{l}\text { Islamic Republic/ central government and } 31 \\
\text { provinces }\end{array}$ & $79926000^{3}$ & $56 * *$ & 44 & $\sqrt{ }$ & $\sqrt{ }$ & $\sqrt{ }$ & $\sqrt{ }$ & $\sqrt{ }$ & $\sqrt{ }$ \\
\hline
\end{tabular}

Source: https://data.worldbank.org/

${ }^{2}$ Source: https://www.amar.org.ir/

${ }^{3}$ Primarv care. retail clinics. etc 
sists of doctors' office, clinics, and limited surgery centers. To better understand ambulatory care, we should consider the overall characteristics of the health system of countries. Table 1 shows the ambulatory care in overall health system in the selected countries.

Canada: All the population is covered by Medicare and the provinces are in charge of providing health services for the area according to the health law of the country. Particular services are covered by Medicare and the other services are covered by private health insurance. Most general physicians work in their own office and are paid as fee-for-service. Specialized services are provided mainly in hospitals. Only $24 \%$ of the specialist physicians were working in private offices of clinics in 2014. The federal government regulates the safety and effectiveness of the specialists $(19,20)$.

Germany: Health insurance is mandatory for all the population. The nongovernmental and non-for-profit illness founds and the private health insurances compete for the population coverage. Although ambulatory care physicians work in their office, almost $25 \%$ of them work in the public sector at the same time. In $2014,48 \%$ of the 109 600 accredited physicians were family physicians and $52 \%$ specialists. Moreover, about 2000 multispecialty clinics exist in which 13000 physicians work. Regulation is delegated to a federal joint commission consisting of the associations of the illness founds and the associations of the providers. Regional associations are in charge of accreditation of the physicians and assuring the requirements and are the financial intermediaries between the illness founds and the ambulatory care physicians (21-24).

Turkey: The Ministry of Health, universities, and private sector provide the health care. Ambulatory care is provided by hospitals. In addition, there are private offices of the general and specialist physicians and ambulatory care clinics. The ambulatory part of the public and private hospitals, private offices, and ambulatory care centers are the main components of the ambulatory care. Specialist ambulatory care in the private sector is provided at specialist clinics of the private hospitals, full-time and parttime private physicians, and private ambulatory centers, all of which are for-profit (25).

UK: The National Health Services (NHS) provide health care for the $80 \%$ of the resources of the NHS and is controlled by primary care trusts, which contract physicians and hospitals for provision of the health services in the defined areas. Specialists are employees of the hospitals, yet most of them have private patients too. Primary health care is provided by private providers that have an- nual contracts with the trusts. Specialists choose to work in public or private hospitals. It is estimated that $55 \%$ of the physicians worked in private sector in 2006 (26).

USA: A range of public and private organizations are involved in regulation and financing of the health care provision. Most physicians work in the private sector with various payment mechanisms based on the payer body. Specialist physicians can work in both hospitals and private offices. The ambulatory care is provided at private offices, independent surgery center, day surgery departments of the hospitals, private clinics, and the non-forprofit comprehensive health centers. It is reported that over $75 \%$ of the surgeries were performed in ambulatory care in $2010(27,28)$.

Iran: Health care providers include government, public nongovernmental, private, and charity. Ambulatory care is provided in hospitals, general and specialty clinics, limited surgery centers, private offices of the general and specialist physicians, offices of paramedical, and other organizations (29).

\section{Responsible body for supervision of ambulatory care}

The next question on the ambulatory care is that who is responsible for supervision. Table 2 shows the responsible body for supervision of ambulatory care in the selected countries; these dimensions were extracted based on the literature and reviews of the countries' health system.

Canada: To improve the governance, non-for-profit organizations are working at the national level in 3 domains: monitoring and evaluation of health system performance by the Canadian Patient Safety Institute; communicating with the society about health and health care by the Canadian Institute for Health Information; and support of information systems by the Canada health info way. There are 3 main approaches for supervision of the health care providers in Canada: licensure for professionals, certificate of activity, and the activity control system, which supervises particular services. Most providers are supervised by professional associations that assure standards of quality of services (20).

Germany: Responsibility of supervision of ambulatory care is delegated to regional and federal associations of the physicians. The main responsibility of the Ministry of Health is to assure and to maintain the public health insurance system (30). Providers of the ambulatory care are required to establish an internal system for quality management according to the guidelines of the Federal Joint Committee. Regional associations of the physicians are required to establish an external system for quality man-

Table 2. Who is responsible for supervision?

\begin{tabular}{lccc}
\hline Country & & Who is responsible for supervision? & \\
\cline { 2 - 4 } Canada & Central government $\left(\mathrm{MOH}^{*}\right)$ & Local government (province or territory) & NGO** (or self-governed) \\
Germany & $\sqrt{ }$ & & $\sqrt{ }$ \\
Turkey & $\sqrt{ }$ & $\sqrt{ }$ & $\sqrt{ }$ \\
UK & $\sqrt{ }$ & $\sqrt{ }$ & $\sqrt{ }$ \\
USA & $\sqrt{ }$ & & $\sqrt{ }$ \\
Iran & & & \\
\hline$*$ Ministry of health & &
\end{tabular}


agement based on quality circles (31). The Institute for Quality and Transparency as a coworker of the Federal Joint Committee is responsible for quality assurance of the services. Furthermore, requirements of quality management in ambulatory care are described in Quality Management Directive by the Federal Joint Committee (2009). This is beside the voluntary accreditation of the ambulatory services $(23)$.

Turkey: The Ministry of Health is the only agency with the right to supervise health care providers in the public and private sectors. This is practiced by several departments of the Ministry. The Ministry defines and evaluates the quality of care standards for public and private providers. All private hospitals, clinics, laboratories, and diagnosis centers should obtain a license from the Ministry of Health (25).

UK: Health care providers obtain a license and are monitored and supervised by the Care Quality Commission (CQC). This entity determines legal requirements of the providers, including hospitals, homecare, and offices. It also observes all health and social cares. The monitor is the regulator of the financial part of the health sector and determines the legal frameworks of the financial works related to the providers. These 2 NGOs are accountable to parliament. All healthcare providers (including organizations, cooperatives of the specialists, and individual providers) should register in CQC and their performance should be monitored according to national standards of quality. This monitoring may also include visiting the providers by the CQC and the national survey of the patients (26).

USA: The Department of Health and Human Services is the main federal entity in charge of health of the population. The organizations responsible for regulating the ambulatory care include Centers for Medicare and Medicaid Services (CMS) and Agency for Healthcare Research and Quality, which are responsible for monitoring the performance, outcomes, effectiveness, clinical guidelines, safety, patient experiences, health information, and health disparities. Physicians, nurses, and other professionals are accredited by licensing boards in each state. In addition to the regulations of each state, physicians are monitored by the CMS at the federal level, which determines the reimbursement criteria. The Institute of Medicine (IOM) as an independent non-for-profit organization acts as a consulting body in policymaking for health promotion. The National Committee for Quality Assurance is the main body for accreditation of private care and is responsible for accreditation of new services in the health market (27).

Iran: Supervision of ambulatory care is performed by the Ministry of Health and Medical Education and medi- cal universities, which are the executive arm of the Ministry. Within the medical universities, the Deputy for Treatment is responsible for supervision of the health services, including the ambulatory care. The deputy of health of the medical universities supervises the hygiene of the ambulatory care centers, and the deputy of food and drug also supervises the availability and use of medicines. Outside the Ministry, the health insurance organizations separately monitor the contracted centers. The Medical Association (Nezam Pezeshki) also has a role in supervision by granting and extension of working licenses for physicians and paramedics (29).

\section{Supervision mechanisms}

Table 3 shows the supervision mechanisms in the selected countries. These dimensions were extracted based on the literature and the reviews of countries' health system.

Canada: The Canadian Foundation for Healthcare Improvement is a federal entity that pursues the improvement of the performance of the physicians by collaboration of the provinces. Accreditation Canada is a non-forprofit organization that provides voluntary accreditation for the health care providers. Unannounced visits are done to the ambulatory care according to existing regulations (20).

Germany: Quality management in the physicians' offices, audits, and licensing are performed by regional associations of the physicians. Complaint management system is considered as a part of quality management program for all health care providers. Accreditation is voluntary but includes the requirements of the Federal Joint Committee (32).

Turkey: All health care providers are supervised by the Ministry of Health and are licensed only when all required standards are met. Monitoring is done periodically to meet standards and in case of receiving complaints about the provision of services, they are investigated (25).

UK: Results of quality assessments in NHS are communicated via NHS Choices. CQC also shares its observation results with the public. Quality framework includes financial incentives for quality improvement. All physicians are required to obtain a license from the General Medical Council and to extend it every 5 years. The CQC makes routine unannounced visits to ensure that the providers meet the standard (32).

USA: Ambulatory surgery centers in 46 states should obtain a license under federal laws. Each state has its own laws for licensing; however, assessment, continuous monitoring, and reporting are required in all states. Of these 46 states, accreditation by NGOs is mandatory in 26

Table 3. Ambulatory care supervision mechanisms in selected countries

\begin{tabular}{|c|c|c|c|c|c|c|c|}
\hline Country & \multicolumn{3}{|c|}{ Supervision mechanisms } & \multicolumn{2}{|c|}{ Voluntary/compulsory } & \multicolumn{2}{|c|}{ Unannounced/announced } \\
\hline & Complaint based & Routine supervision & Accreditation & Voluntary & Compulsory & Unannounced & Announced \\
\hline $\begin{array}{l}\text { Canada } \\
\text { Germany }\end{array}$ & $\sqrt{ }$ & $\begin{array}{l}\sqrt{ } \\
\sqrt{ }\end{array}$ & $\begin{array}{l}\sqrt{ } \\
\sqrt{ }\end{array}$ & $\begin{array}{l}\sqrt{ } \\
\sqrt{ }\end{array}$ & $\begin{array}{l}\sqrt{ } \\
\sqrt{ }\end{array}$ & $\begin{array}{l}v \\
\sqrt{ }\end{array}$ & \\
\hline Turkey & $\sqrt{ }$ & $\sqrt{ }$ & & & $\sqrt{ }$ & $\sqrt{ }$ & \\
\hline UK & $\sqrt{ }$ & $\sqrt{ }$ & & & $\sqrt{ }$ & $\sqrt{ }$ & \\
\hline USA & $\sqrt{ }$ & $\sqrt{ }$ & $\sqrt{ }$ & $\sqrt{ }$ & $\sqrt{ }$ & $\sqrt{ }$ & \\
\hline Iran & $\sqrt{ }$ & $\sqrt{ }$ & & & $\sqrt{ }$ & $\sqrt{ }$ & \\
\hline
\end{tabular}


Table 4. Consequence of Supervision

\begin{tabular}{|c|c|c|c|c|c|c|c|}
\hline \multirow[t]{2}{*}{ Country } & \multicolumn{7}{|c|}{ Consequence of Supervision } \\
\hline & $\begin{array}{l}\text { Tariffs depend } \\
\text { on results }\end{array}$ & $\begin{array}{l}\text { Suspension or } \\
\text { revocation of } \\
\text { license }\end{array}$ & $\begin{array}{l}\text { Effect on } \\
\text { contracts }\end{array}$ & $\begin{array}{c}\text { Change in stars or } \\
\text { degree }\end{array}$ & $\begin{array}{c}\text { Financial } \\
\text { penalty }\end{array}$ & $\begin{array}{l}\text { Denial of license } \\
\text { for professionals }\end{array}$ & Re-training \\
\hline Canada & & $\sqrt{1}$ & & $\sqrt{1}$ & & & \\
\hline Germany & $\sqrt{ }$ & $\sqrt{ }$ & $\sqrt{ }$ & & & $\sqrt{ }$ & $\sqrt{ }$ \\
\hline Turkey & & $\sqrt{ }$ & & & & & \\
\hline UK & & $\sqrt{ }$ & & & $\sqrt{ }$ & $\sqrt{ }$ & \\
\hline USA & & $\sqrt{ }$ & $\sqrt{ }$ & $\sqrt{ }$ & & $\sqrt{ }$ & \\
\hline Iran & & $\sqrt{ }$ & $\sqrt{ }$ & & $\sqrt{ }$ & $\sqrt{ }$ & \\
\hline
\end{tabular}

states and it is optional in the other 18 states. All surgery centers are observed by Medicare, which assesses and monitors the ambulatory centers for licensure requirements (27).

Iran: Three types of supervision are in place: based on telephone-based or paper-based patient complaints to the deputy of treatment of the medical universities, based on routine visits to the health care organizations, customer reports, or requests from other entities. All observations are compulsory, unannounced, and done by predefined standard checklists (33).

\section{Consequences of supervision}

Consequences of the performed supervision on the ambulatory care in the selected countries are presented in Table 4.

Canada: Lack of compliance with the requirements and standards of quality and safety results in suspension or revocation of license as well as decreased degree of accreditation (22).

Germany: Consequences of the supervision of ambulatory care range from mandatory retraining to denial of contracts and license (32).

Turkey: Punishments for the noncompliance with standards include revocation of license or its temporary suspension until the standards are met (25).

UK: After overseeing outpatient centers, the CQC requests a defective action plan to fix the defects. Other consequences include written note for the providers, limiting or suspension of services provision, and financial penalties (32).

USA: The first consequence of observations is changes in payments to the providers. Any change in accreditation level of the provider results in payments. Public communication is the other consequence of quality and safety observations in ambulatory care (32).

Iran: After monitoring, in case of minor problems, a verbal warning and in case of more serious problems, a written warning is given and is included in the records. Major defects are recorded in history of the individual provider, and financial penalties are also in place. Other potential consequences include rejection of expansion request of the provider organization; suspension or revocation of the license; revocation of the license of the technical manager of the hospital; denial of services for the individual provider as permanent or time-bounded inationwide or in a particular city; and changes in the payments according to the accreditation level (33).

\section{Discussion}

All health systems employ some regulations and frameworks for quality assurance and improvement and safety of the health care services. The responsible bodies for this function range from local and national governments to nongovernmental organizations. Supervision in the studied countries was mostly unannounced and compulsory. Moreover, accreditation of the ambulatory care exists as compulsory and voluntary. Consequences of the supervision of ambulatory care in the studied countries included suspension or revocation of license, effect on payments to the provider, and change in popularity of the provider by public communication of the results.

Supervision of the ambulatory care in the studied countries was mostly with the NGOs. Turkey had a centralized and governmental system of supervision (25), but professional associations and NGOs were involved in other countries (32). The more centralized political system of a country, the more centralized supervision system for ambulatory care. With some precautions we can conclude that the NGOs have a more highlighted role in the supervision of the health services in more democratic political systems which means more social responsibility in the services. In Iran professional associations have been involved in developing supervision standards and checklists by the Ministry of Health. The Medical Association is also involved in licensure. Upper health policies of Iran declare that the supervision task should be separated from the provision function of the Ministry of Health (34). To some extent, this is achieved about the hospital services and can be repeated in accreditation of ambulatory services.

Among the mechanisms of supervision in ambulatory care, the complaint management system was in place in all studied countries and its results highly affect the providers. Field visits were also running in all studied countries in the form of announced or unannounced visits. Compulsory accreditation was not common for ambulatory care and was mainly for the inpatient services of the hospitals. Yet, it existed in voluntary form in Canada and Germany $(22,23)$ and in compulsory form in the USA (32). The result of accreditation is granting of degrees and credits to providers, which will affect their payment system. We recommend voluntary accreditation of ambulatory services in Iran as well as communication of the accreditation results.

Provision of the health services by the private sector increases the choice options of the patients, but it requires more supervision. In this regard, public communication of results may be helpful and increase the competition of the 
providers for quality and safety of the services (35). In most countries the supervision of the ambulatory care is performed compulsorily and by organizations other than the provider organization. This is important in case of Iran, because both service provision and supervision are performed by organizations that are affiliated to the Ministry of Health Iran. This has led to inefficiency of the supervision and improper quality of services along with violation of regulations (36).

Findings of the study showed that the field visits are performed both announced and unannounced. In most monitoring systems scheduled monitoring is performed at regular intervals or at least annually (37); in addition, unannounced visits are made to investigate complaints.

The most important aspect of supervision, irrespective of its method and type, is the application of results. Studies show several tools can cause the providers to take the assessments seriously (32). If the assessment results have no effect or have little positive or negative effect on providers, supervision would not lead to change in their behaviors (38). Since supervision is a costly task, its results should be followed up and applied. In the Iranian health system, the impact of monitoring outpatient services is so mild that in practice it cannot play a deterrent or corrective role, and thus does not have any effects on performance and behaviors of the providers. Problems in regulations and conflict of interest have reduced the power of supervision as an important function. Thus, benchmarking from successful countries can be very useful.

\section{Conclusion}

Improving the supervision and assessment of ambulatory care services requires an effective structure with separation of provider and supervisor and involvement of the professional associations. Passing effective laws and regulations would be critical in this regard. It is suggested that the Ministry of Health Iran allocate sufficient human and financial resources for follow up of the supervision results, force the providers to comply with the standards and regulations, and implement new supervision approaches such as accreditation in ambulatory care.

\section{Acknowledgment}

This study was part of a PhD thesis supported by Iran University of Medical Sciences, Tehran, Iran (Grant number: IUMS/SHMIS_1396.9321532001; Ethical code: IR.REC.IUMS.1396. $\overline{9} 321532001)$.

\section{Conflict of Interests}

The authors declare that they have no competing interests.

\section{References}

1. Souba W, Notestine M, Way D, Lucey C, Yu L, Sedmak D. Do deans and teaching hospital CEOs agree on what it takes to be a successful clinical department chair? Acad Med. 2011;86(8):974-981.

2. Schwartz R, Pogge C. Physician leadership is essential to the survival of teaching hospitals. Am J Surg. 2000;179(6):462-468.

3. Revisioninig in managing teaching hospitals. [Internet] $2016 \mathrm{Apr}$ 8[updated 2016 May 11; cited 2016 Apr 5]. Available from: http:/www.shahrekhabar.com/analysis/1431162240828954
4. Health infrastructure [Internet]. National Center for Biotechnology Information; 2017 [cited 2017 Feb 15]. Available from: https://www.ncbi.nlm.nih.gov/books/NBK144006/.

5. Badlani N. Ambulatory surgery center ownership models. J Spine Surg. 2019 Sep;5(Suppl 2):S195.

6. Habibnejad M. Collection of management golden keys. Tehran: Arg publisher. 2007.

7. Pezeshkian M. The rules of establishment and use of hospitals [Internet]. [Updated 2016 Nov 8; cited 2016 Sep 11]. Available from: http://markazsalamat.behdasht.gov.ir/uploads/358_1892_6_1.pdf.

8. BastaniParizi M. Management theories of theory to action. Shiraz. High Institute of Banking. Central Bank of Islamic Republic of Iran. 2007.

9. Lack of education and caring space in hospitals, a major problem in teaching hospitals. [Internet] 2016 Apr 25[updated 2016 Apr30; cited 2016 May 2].Available from: http://isna.ir/news/93120301158.

10. Maleki MR, FatehpanahA, Gouhari MR. Performance of Hashemi Nejad hospital based on knowledge management criteria according to health and education category of Malcolm Baldrige model. J Health Inf Manag. 2012;8(4):580-587.

11. Dehghani M, Heivi Haghighi M, Tavassoli Farahi M. Comparing the emergency center information management system of teaching and non-teaching hospitals of Hormozgan university of medical sciences. Mod Inf Sci. 2015;1(2):61-70.

12. Nasrollahpour Shirvani D, Mouodi S. Evidence-Based policymaking in health system and its achievements and challenges in Iran. Babol. Babol University of Medical Sciences and Health Care Services. Nooj Publishing. 2013.

13. Mohseni M, Seyedin H, Hoseini A, Monshadi M, Asadi H. A survey on the responsibility of teaching hospitals of Tehran university of medical sciences. Hosp J. 2016;14(53):95-100.

14. Stella M, Pereira M, Cristina A. Assessment of teaching health care integration and performance in university hospitals. Performance and integration between teaching and healthcare. Rev Saude Publica. 2010;44(4):581-90.

15. Javadin R, Kabiri A. A comprehensive review on the organization and management theories. Tehran: Negahe danesh. 2001.

16. Asefzadeh S, Rezapour A. Health planning. Qazvin: Qazvin University of Medical Sciences; 2008.

17. Arab M, Kavousi Z, Ravangard R, Ostovar R. Health Insurance Systems. Tehran: Iranian Student Book Agency; 2011.

18. Abolhallaje M, Jafari M, Seyedin H, Salehi M. Financial Management Reforms in the Health Sector: A Comparative Study Between Cash-based and Accrual-based Accounting Systems. Iran Red Crescent Med J. 2014 Oct;16(10).

19. Collier R. National physician survey: EMR use at 75\%. Can Med Assoc J. 2015;187(1):E17.

20. Marchildon G. Canada: Health system review. 2013.

21. Auras S, Geraedts M. Patient experience data in practice accreditation - an international comparison. Int J Qual Health Care. 2010;22(2):132-9.

22. Mossialos E, Wenzl M, Osborn R, Sarnak D. 2015 international profiles of health care systems: Canadian Agency for Drugs and Technologies in Health; 2016.

23. Döring A, Paul F. The German healthcare system. EPMA J. 2010;1(4):535-47.

24. Brökelmann J. Comparison of hospital-and office-based ambulatory surgery in Germany: surgery in small free standing units offers many advantages. Amb Surg. 2012;17:83-5.

25. Tatar M, Mollahaliloğlu S, Şahin B, Aydın S, Maresso A, Hernández-Quevedo C. Turkey: Health system review. 2011.

26. Cylus J, Richardson E, Findley L, Longley M, O'Neill C, Steel D. United Kingdom: health system review. 2015.

27. Rice T, Rosenau P, Unruh L, Barnes A, Saltman R, Van Ginneken E. United State of America: health system review. 2013.

28. Hollenbeck BK, Dunn RL, Suskind AM, Strope SA, Zhang Y, Hollingsworth JM. Ambulatory surgery centers and their intended effects on outpatient surgery. Health Serv Res. 2015;50(5):1491-507.

29. Supervision on medical, paraclinical and hospital institutions. [cited 2020 Feb 15]. Available from: http://Medcare.behdasht.gov.ir

30. Ettelt S, Nolte E, Thomson S, Mays N. A review of the role and responsibilities of national ministries of health in five countries. London: London School of Hygiene and Tropical Medicine. 2007.

31. Breckenkamp J, Wiskow C, Laaser U. Progress on quality management in the German health system-a long and winding road. 
Health Res Policy Syst. 2007;5(1):7.

32. Schweppenstedde D, Hinrichs S, Ogbu U, Schneider EC, Kringos DS, Klazinga NS, et al. Regulating quality and safety of health and social care. Final report. Rand Europe (UK); 2014.

33. Instructions for treatment supervision. [cited 2020 Feb 25]. Available from: http://Treatment.sbmu.ac.ir

34. A Review of General Health Policies Announced by the Supreme Leader of Iran. 2. 2018;2(1):32-53.

35. Chokshi DA, Rugge J, Shah NR. Redesigning the regulatory framework for ambulatory care services in New York. The Milbank Quarterly. 2014;92(4):776-95.

36. Movahhed T, Arab H, Hashemi S, Mohammadzadeh Z. Evaluation of dental complaints received by the Mashhad medical council from 2001 to 2011. Sci J Forensic Med. 2016;22(1):31-7.

37. Risso-Gill I, Legido-Quigley H, Panteli D, Mckee M. Assessing the role of regulatory bodies in managing health professional issues and errors in Europe. Int J Qual Health Care. 2014;26(4):348-57.

38. Joudaki H, Rashidian A, Milanifar AR. Review of relevant legislation about physicians misconduct in Iran. Sci J Forensic Med. 2010;16(3):215-223. 